\title{
Optimal Dietary Diversity and its Associated Factors among Children Aged 6-23 Months in Bale Zone, Southeast Ethiopia: aCommunity Based Cross-Sectional Study
}

\author{
Tomas Benti Tefera ${ }^{1 *}$, Mekonnen Tegegne ${ }^{1}$, Shumi Bedada ${ }^{2}$, Abebe Amare ${ }^{3}$ \\ ${ }^{1}$ Department of Public Health, Madda Walabu University, Goba Referral Hospital, Bale Goba, Ethiopia \\ ${ }^{2}$ Department of Public Health, Madda Walabu University, Goba Referral Hospital, Bale Goba, Ethiopia \\ ${ }^{3}$ Department of Nursing, Madda Walabu University, Goba Referral Hospital, Bale Goba, Ethiopia
}

Received: 23 December, 2019; Accepted: 29 January, 2020; Published: 26 february, 2020

*Corresponding author: Tomas Benti Tefera, Department of Public Health, Madda Walabu University, Goba Referral Hospital, Bale Goba, Ethiopia, E-mail: tomasbenti2018@gmail.com

\section{Abstract}

Background: Almost all nutritional related problems are preventable by implementing infant and child feeding strategies. The first two years of life are particularly important to reverse the nutritional problems by achieving dietary diversity feeding.This study assessed optimum dietary diversity and its associated factors among 6-23 months old children in Robe town, southeast Ethiopia.

Methods: Community based cross sectional study design with simple random sampling was employed to include 517 children 6-23 months of age paired with their mothers in Robe town. Data were collected using pre-tested and structured questionnaire. Data were entered into EpiData version 3.1 and analysis was performed using SPSS version 20. Descriptive analysis was done for appropriate variables. Multivariate logistic regression analyses were used to identify factors associated with optimal dietary diversity practices among children aged 6-23 months.

Results: Five hundred eight samples were included in the analysis making response rate of $98 \%$. The optimal dietary diversity practice in the study area was $23 \%$. The dominant food groups consumed by children aged 6-23 months in the study area were Grain, roots and tubers and Dairy products. Exposure to media (AOR=3.99, $95 \% \mathrm{CI}, 1.97: 7.77)$, secondary and above maternal education ( $\mathrm{AOR}=3.21,95 \% \mathrm{CI}, 1.05: 9.85)$, and maternal knowledge about diet diversification ( $\mathrm{AOR}=8.5,95 \% \mathrm{CI}, 4.95: 14.58$ ) were found positive significant predictors of optimal dietary diversity practice in the study area.

Conclusion: This study concluded that optimum dietary diversity among children aged 6-23 months in the study area is low. Exposure to media and maternal education, maternal knowledge on dietary diversification were found as positive predictors of optimal dietary diversity practice for the children aged 6-23 months. So, inclusion of child nutrition programs different mass medias in the country and encouraging women education would contribute for better dietary diversity of these children.

Keywords: Children aged 6-23 months; Dietary diversity; Nutrition; Southeast Ethiopia

Abbreviations: AOR: Adjusted Odds Ratio; CF: Complementary Feeding; CHIS: Community Health Information System; COR: Crude Odds Ratio; DDS: Dietary Diversity Score; EDHS: Ethiopian Demographic Health Survey; IYCF: Infant and Young Child Feeding; SDG: Sustainable Development Goals; WHO: World health organization

\section{Introduction}

Suboptimal infant and young child feeding practice is highly prevalent in low and middle-income countries, contributing to irreversible outcomes of nutritional problems, children mortality and overall disease burden [1-3].

Globally, out of 10.9 million under5-year deaths that occur, malnutrition is directly or indirectly responsible for $60 \%$ of death. More than 3.4 million under5-year children die each year due to inappropriate feeding practices. Of which, two-thirds of these deaths are associated with inappropriate feeding practices during the first 2 years of life [4].

Dietary diversity is a proxy for adequate micronutrient density of foods [5]. Appropriate dietary diversity feeding for Infant and young child during the first two years of life improves child growth and development, reduces morbidities, mortalities, and risks of other chronic diseases. However, only less than a fourth of children aged 6-23 months get recommended diversified diet globally [6].

World health organization recommend that children aged 6-23 month should consume foods among the seven food groups that includes: Grains, roots and tubers; Legumes and nuts; Dairy products; Flesh foods (meats/fish/poultry); Eggs; Vitamin A-rich fruits and vegetables; and other fruits and vegetables. In addition to breast feed, child must feed four and above and non-breast feed child should feed milk and milk products in addition to the 
four food groups consumption [7].

The Sustainable Development Goals (SDGs) aimed to ensure healthy lives and promote well-being for all children. The SDG 3 target 3.2 aimed to end preventable deaths of newborns and under five year children by 2030 [8].

United Nations has emphasized that implementations to achieve the SDGs should acknowledge the nutrition priorities in which all of the SDGs have relations with nutrition. Improvements in human nutrition represent both a maker and a marker of sustainable development [9].

In an effort to accelerate the reduction of undernutrition, the Government of Ethiopia developed the National Nutrition Strategy and the National Nutrition Programmes (NNP) [10, 11]. Several additional initiatives also embody the government's commitment for improved nutrition. The Seqota Declaration (2015-2030) aims to eliminate all forms of malnutrition among children under age 2 by 2030 [12].

Despite these efforts to increase dietary diversity feeding practice in Ethiopia, the problem is still high. According to Ethiopia Demographic and Health Survey report only 7\% of children age 6-23 months meet the minimum acceptable dietary standards and only $14 \%$ of children had an adequately diverse diet [13]. This indicates that still low dietary diversity practice in children age 6-23 months. Hence, this study aimed to identify the magnitude of optimum dietary diversity and its associated factors among children aged 6-23 months at the study area.

\section{Materials and Method}

\section{Study Design and Setting}

Community based cross-sectional study was conducted in Bale zone, robe town of south east Ethiopia, located at about 430 kilometers from the capital, Addis Ababa. Bale highland (in which the town located) is highly suitable for agriculture and is known for potential production of wheat and barley in Ethiopia. According to Robe Town Health of report of 2017, the town has a total of three kebeles and has 67,124 total populations, from which total of children 6-23 months of age are estimated to be 2,873. A study was conducted from March 28 to April 302017.

\section{Sample Size Determination}

Sample size was determined by using OpenEpi, Version 3. The assumption made includes: the proportion of children practiced minimum dietary diversity, $12.6 \%$, 95\% level of confidence and margin of error $3 \%$ to get a sample size of $470[14]$. After considering $10 \%$ for non-response rate the sample size was increased to 517.0

\section{Sampling Procedure}

The study town, Robe town has three main kebeles: Baha Biftu, Oda Robe and Café Donsa. Based on the town health office data of 2017, there were 2873 households having children 6-23 months of age during the study period. Of these, 543 households were from Baha Biftu kebele, 990 were from Oda Robe and
1339 households were from Café Donsa. Based on these data, the determined sample size was proportionally allocated to each three kebeles. Sampling frame was constructed based on community-based health information system of family folder in health posts. Lists of all mothers having children age 6-23 months with Community Health Information System (CHIS) number in selected kebeles were used to select the respondents through computer generated methods of random sampling. When the mother/caregiver is not available at the time of data collection, another one-timerevisitwas made on the next day and were replaced by the next household having a child of 6-23 months of age if absent on this visit.

\section{Data Collection Tool and Procedures}

Dietary diversity score tool was adapted from the World health organization IYCF guideline [15]. Questions regarding maternal and child demographic characteristics was adapted from Ethiopia Demographic Health Survey [13]. Questionnaire was first prepared in English and translated into Afaan Oromo, which later on, were translated into English for consistency check. Finally, Afaan Oromo version questionnaire was used to collect data. Data were collected by ten diploma holder health extension workers. Data on dietary diversity were collected through face to face interviewing of mothers having children aged 6-23 months by allowing them freely to recall the type of food items they feed to their child/children within the last 24 hours. One-day training was given for data collectors on the questionnaire and data collection procedures. Three supervisors were assigned and checked completeness of the questionnaire daily with principal investigators and data collectors.

\section{Study Variables}

Dietary diversity (dichotomized as optimal /suboptimal) was dependent variable and the Independent variables include Parental level variables including maternal age, maternal education, maternal knowledge, maternal occupation, and marital status of the mother, place of delivery, religion, paternal education and paternal occupation. Child level variables were age of the child, sex, birth order of index child, growth monitoring follow-up and breast-feeding status. Household level variables included were exposure to media, number of under-five aged children, family size, and monthly income, type of latrine and source of drinking water.

\section{Operational Definition \\ Optimal Dietary Diversity:}

Dietary diversity was defined as optimal if children (aged 6-23 months) received foods from at least four of seven food groups (1) Grains, roots, and tubers, (2) Legumes and nuts, (3) Dairy products, (4) Flesh foods, (5) Eggs, (6) Vitamin-A rich fruits and vegetables, (7) Other fruits and vegetables, within the preceding $24 \mathrm{~h}$ of interview and Sub-optimal dietary diversity is if children of age group were receiving three foods or fewer within $24 \mathrm{~h}[7]$. 


\section{Statistical Analysis}

Data were entered into EpiData version 3.1 with double entry verification. Analysis was performed using SPSS version 20.0. Frequency and cross-tabulation were used to present descriptive data. Both the bivariate and multivariable logistic regression analyses were performed to assess the association between dependent and independent variables. Independent variables that showed $\mathrm{P}<0.2$ at $95 \% \mathrm{CI}$ in the bivariate logistic regression analysis were included in multivariable logistic regression model. $\mathrm{P}<0.05$, with $95 \% \mathrm{CI}$, was considered to declare the variables significantly associated with the dependent variable.

\section{Results}

Of the total 517 sampled mothers' / care takers who had children 6-23 months, 508 of them participated in the study with the response rate of $98 \%$.

\section{Socio-Demographic Characteristics of Mothers}

One hundred ninety-nine (39.2\%) of respondents were in the age group 25-29 years, 337 (66.3\%) were Muslim religion followers and $470(92.5 \%)$ were Oromo in ethnic group. Concerning the educational status of the mothers, 61 (12\%) had no formal education, $245(48.2 \%)$ were completed primary education $202(39.8 \%)$ were completed secondary education and above. Forty-five (9\%) of fathers of children had no formal education, and 180 (35.4\%) of them were daily laborers Table 1.

Table 1: Paternal characteristics of the children included in the study in Robe town, Southeast Ethiopia, From April to May 2017

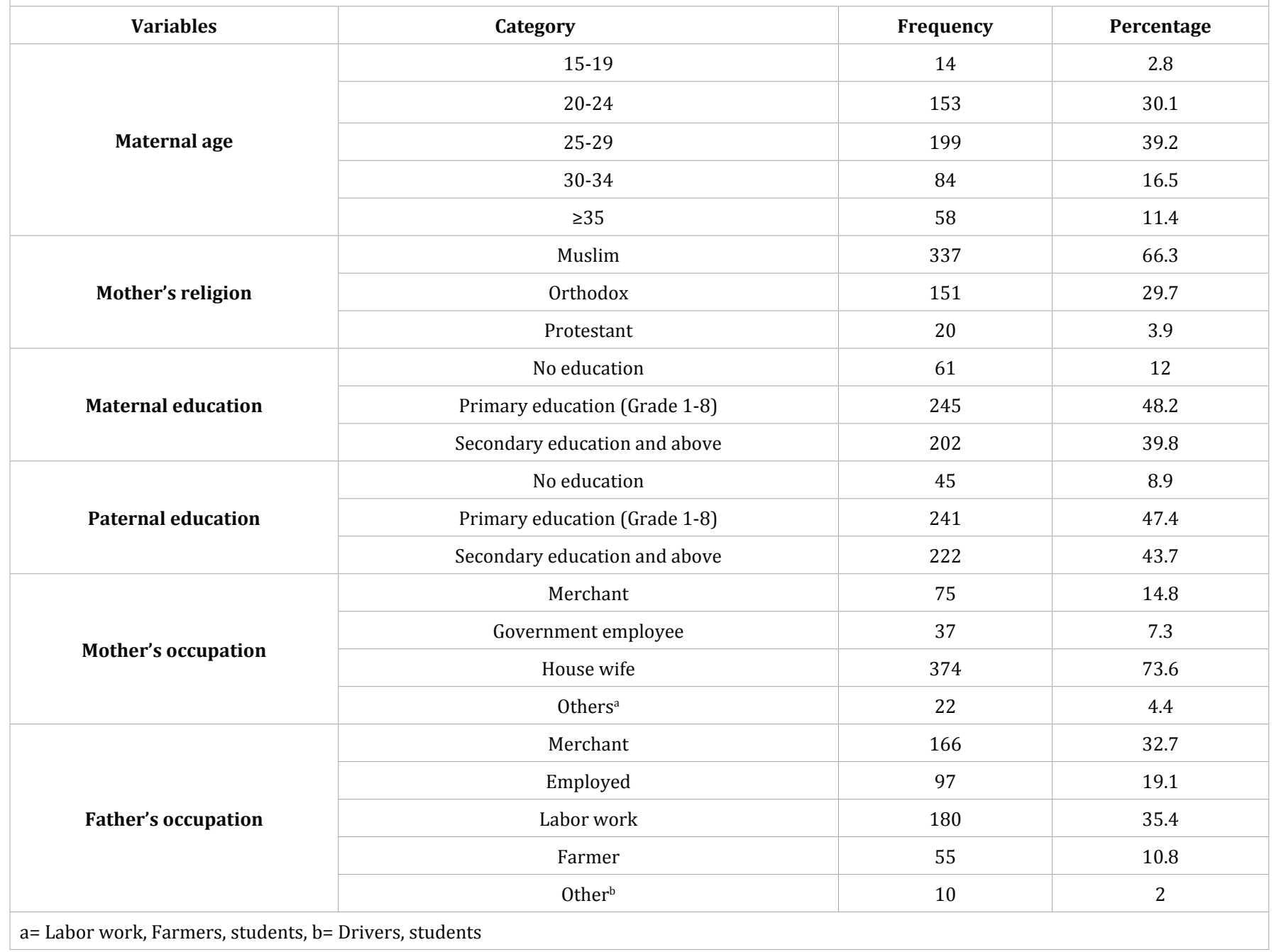




\section{Household Level Characteristics}

Regarding households of the study participants, 293 (57.7\%) of households had only one under five children and 261 (51.4\%) of households had five and above total family sizes. Almost all mothers involve on decision of the type of the food to provide for their child at household level and 153 (30\%) of total mothers did not have media exposure.

\section{Child Level Characteristics}

From the total children included 353(69.5\%) were in the age group 12-23 months. Four hundred seventy-two (92.9\%) children were born at health institutions (hospital or health center). The majority of children 446 (87.8\%) conducted growth monitoring follow up Table 2

Table 2: Child characteristics of the children included in the study in Robe town, Southeast Ethiopia, From April to May 2017

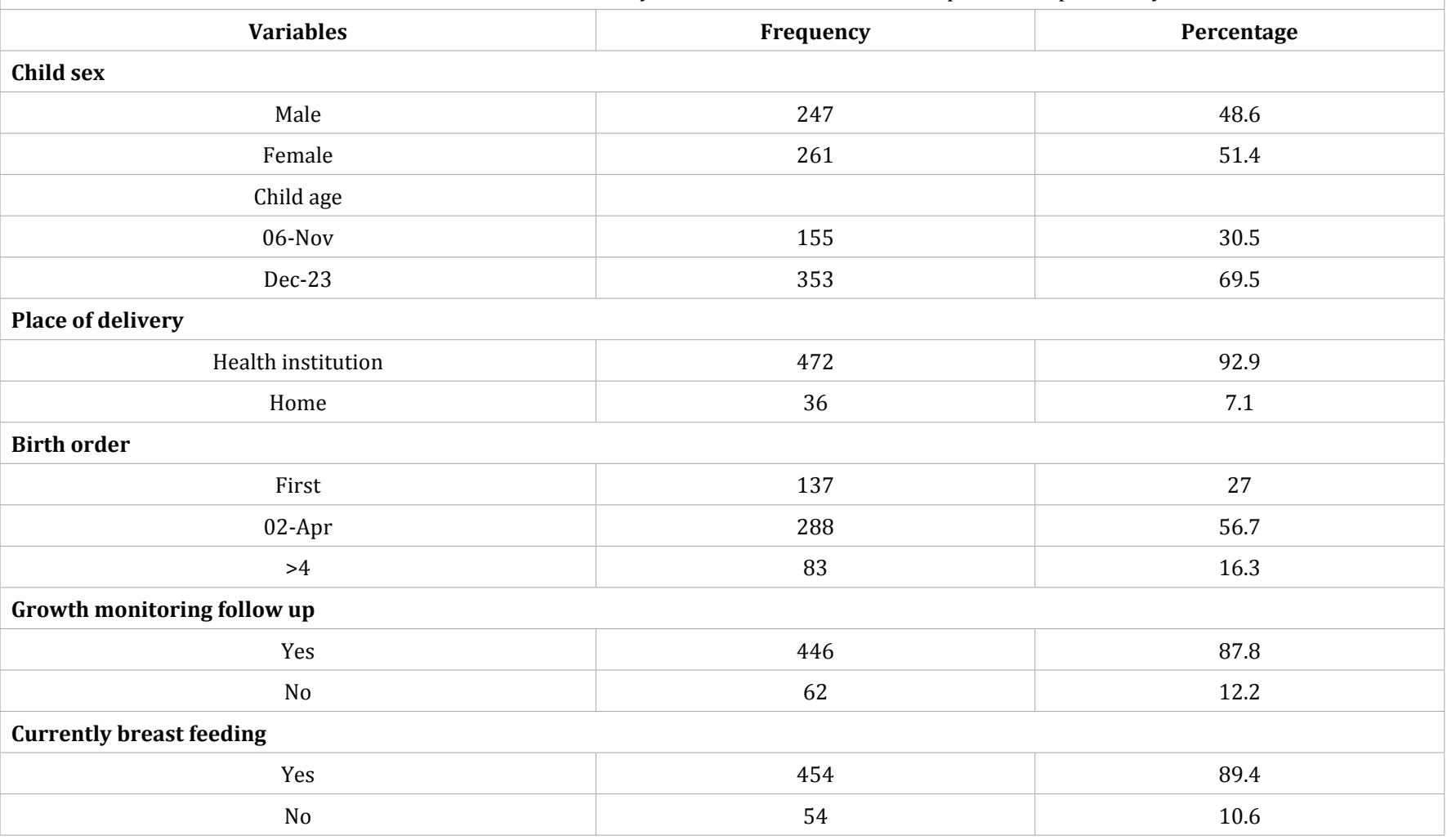

\section{Water and Sanitation Characteristics of Households}

Two hundred thirty-eight (47\%) households use an improved latrine type, which include pit latrines with slab; ventilated improved pit latrines and other improved type of latrines (pour flush toilets discharge into septic tank). However, more than half, $53 \%$ of households use an unimproved type of latrine. The most common type of unimproved toilet facility is a pit latrine without slabs, used by $52 \%$ of households of the study participants.

The principal sources of drinking water for the households were improved source. Four hundred twenty-four (83.5\%) of households were using piped water and fewer households 2 $(0.4 \%)$ were using unimproved source of drinking water.

\section{Dietary Diversity Practices}

\section{Types of Food Groups Practiced}

Minimum Dietary Diversity Practice
According to mothers' report of what their child had consumed in the preceding 24 hours of the day of the data collection, the mean dietary diversity score out of the seven food groups were 2.89 with SD of 1.17 . The study revealed that 118 (23\%) of infants and young children consumed the required minimum number of food groups ( $\geq 4$ food groups). The rest 390 (77\%) of infants and young children in the study area practiced below the minimum recommended dietary diversity for children 6-23 months of age Figure 1.

\section{Factors Associated with Dietary Diversity Among Children Aged 6-23 Months}

Among variables evaluated in bivariate and multivariable logistic regression analysis child age, mothers' education, media exposure, fathers' occupational status and knowledge of mothers on food diversification were the only variables which have shown statistically significant and independent association with minimum dietary diversity practices. The analysis indicated that 


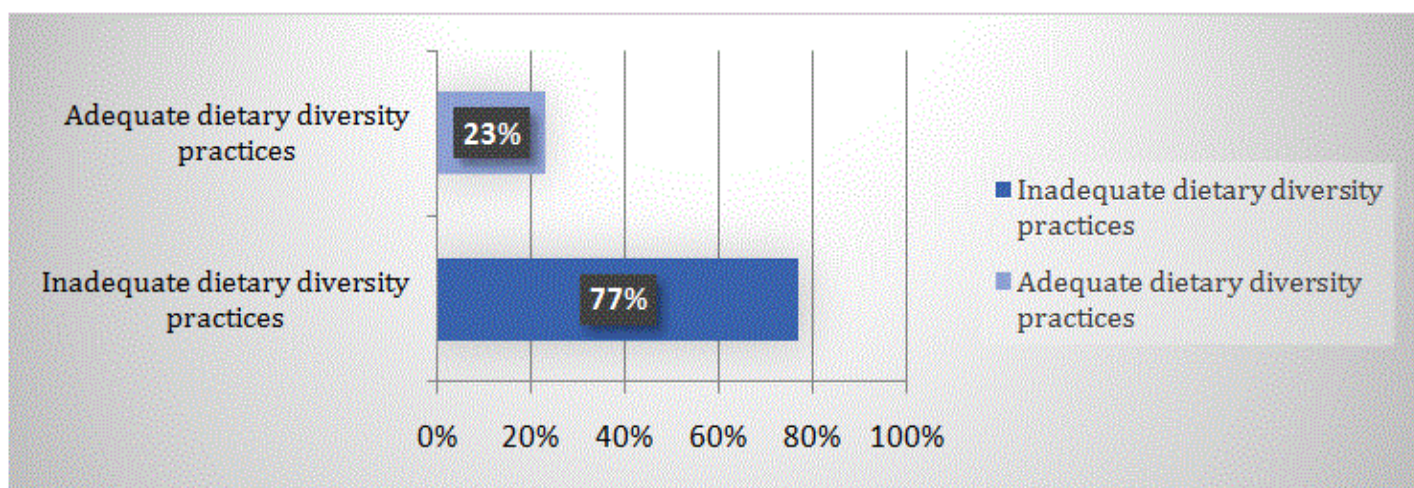

Figure 1: Optimal dietary diversity practice of infants and young children in Robe town Southeast Ethiopia, From April to May 2017

children aged 12-23 months were more likely to fed minimum dietary diversity compared with children who were aged 6-11 months (AOR=2.99, 95\% CI, 1.65:5.42). This study also indicated children of mothers having secondary and above education level were more likely to be fed diversified food. It showed that the odds of feeding their baby minimum dietary diversity among mothers whose education level was secondary or above were nearly 3 times higher than those mothers who have no formal education $(\mathrm{AOR}=3.21,95 \% \mathrm{CI}, 1.05: 9.85)$.

Mothers who were exposed to media frequently had higher odds of feeding their children diversified diet than those mothers who had not attended to the media (AOR=3.99, $95 \%$ CI, 1.97:7.77). The study showed that mothers $15-24$ years of age were more likely to feed their child diversified food than older mothers. Children whose mothers aged 30 or above years were $56 \%$ less likely to meet minimum dietary diversity score than children whose mothers were aged 15-24 years (AOR=0.44, 95\% CI, 0.22:0.87). Mothers who have knowledge about food diversification showed significant association to their habit of dietary diversity feeding practice. Children whose mothers were knowledgeable about food diversification had 8.5 times higher odds of minimum dietary diversity practice as compared to children whose mothers haven't specific knowledge on food diversification (AOR=8.5, 95\% CI, 4.95:14.58) Table 3.

Children whose fathers were daily laborers showed low practice of minimum dietary diversity as compared to children whose fathers were merchants. Children whose father's occupation was merchants were 2 times more likely to get diversified diet than children whose fathers were daily laborers (AOR=2.27, 95\% CI, 1.19:4.33) Table 4 .
Table 3: Type of food children consumed during 24 hours' prior the day of data collection in Robe town, Southeast Ethiopia, From April to May 2017

\begin{tabular}{|c|c|c|}
\hline Variables (Food groups) $^{*}$ & Frequency & Percentage \\
\hline Grain, roots and tubers & 480 & 94.5 \\
\hline Legumes and nuts & 207 & 40.7 \\
\hline Dairy products & 363 & 71.5 \\
\hline Flesh foods (meat) & 54 & 10.6 \\
\hline Eggs & 133 & 26.2 \\
\hline $\begin{array}{l}\text { Vitamin A rich fruit and } \\
\text { vegetables }\end{array}$ & 142 & 28.8 \\
\hline Other fruits or vegetables & 87 & 17.1 \\
\hline
\end{tabular}

\section{Discussion}

This study assessed the magnitude of Optimum dietary diversity and its associated factors for children aged 6-23 months in Robe town of southeast Ethiopia. The magnitude of optimum dietary diversity in this study area was found $23 \%$ that is low. The possible reasons for low dietary diversity practices in the study area could be low practice giving complimentary feeds after six months and the habit of the family (i.e. Preparing the family food together, no food preparation for children alone). Also, low affordability of foods that is not available at home and those foods that are costly are sold from the house instead of feeding their child.

This finding is comparable with the findings from the studies done in Kamba district of Ethiopia 23.3\%, Amhara region 17\% districts of Ethiopia, and Haramaya town of Oromia region 25.2 $\%$ [17-19]. However, higher than findings from the studies done Dejen District of North West Ethiopia (13.6\%), in Dangila of Northwest Ethiopia 12.6\%, Gorche district of southern Ethiopia 
Table 4: Bivariate and multivariate logistic regression analysis for factors on minimum dietary diversity practice among children 6 to 23 months of age in Robe town, Southeast Ethiopia, From April to March 2017

\begin{tabular}{|c|c|c|c|c|}
\hline \multirow[t]{2}{*}{ Predictor variables } & \multicolumn{3}{|c|}{ Optimal dietary diversity score } & \multirow[b]{2}{*}{ AOR $(95 \% \mathrm{CI})$} \\
\hline & Yes & No & COR $(95 \% \mathrm{CI})$ & \\
\hline \multicolumn{5}{|l|}{ Child age (month) } \\
\hline $6-11$ & $21(14)$ & $134(86)$ & 1 & 1 \\
\hline $12-23$ & $97(28)$ & $256(72)$ & $2.42(1.44,4.05)^{* * *}$ & $2.99(1.65,5.42)^{* *}$ \\
\hline \multicolumn{5}{|l|}{ Current BF status } \\
\hline No & $21(39)$ & $33(61)$ & 1 & 1 \\
\hline Yes & $97(21)$ & $357(79)$ & $0.43(0.24,0.77)^{* *}$ & $0.62(0.29,1.31)$ \\
\hline \multicolumn{5}{|l|}{ Place of delivery } \\
\hline Home & $5(14)$ & $31(86)$ & 1 & 1 \\
\hline Health facility & $113(24)$ & $359(76)$ & $1.95(0.74,5.14)$ & $1.32(0.42,4.16)$ \\
\hline \multicolumn{5}{|l|}{ Marital status } \\
\hline Not in union & $1(5)$ & $21(95)$ & 1 & 1 \\
\hline In union & $117(24)$ & $369(76)$ & $6.66(0.89,50.04)$ & $2.10(0.25,17.82)$ \\
\hline \multicolumn{5}{|l|}{ Mothers' decision making } \\
\hline No & $1(7)$ & $13(93)$ & 1 & 1 \\
\hline Yes & $117(24)$ & $377(76)$ & $4.03(0.52,31.17)$ & $3.01(0.28,32.52)$ \\
\hline \multicolumn{5}{|l|}{ Media exposure } \\
\hline No & $14(9)$ & $138(90)$ & 1 & 1 \\
\hline Yes & $104(29)$ & $252(71)$ & $4.07(2.24,7.38)^{* *}$ & $3.91(1.97,7.77)^{* *}$ \\
\hline \multicolumn{5}{|l|}{ Mother's education } \\
\hline No education & $5(8)$ & $56(92)$ & 1 & 1 \\
\hline 1 回 education & $44(18)$ & $201(82)$ & $2.45(0.93,6.48)$ & $1.80(0.60,5.34)$ \\
\hline 2 and above & $69(34)$ & $133(66)$ & $5.81(2.22,15.17)^{* *}$ & $3.21(1.05,9.85)^{*}$ \\
\hline \multicolumn{5}{|l|}{ Maternal age } \\
\hline $15-24$ & $49(29)$ & 118(71) & 1 & 1 \\
\hline $25-29$ & $49(25)$ & $150(75)$ & $0.79(0.49,1.25)$ & $0.61(0.34,1.08)$ \\
\hline$\geq 30$ & $20(14)$ & $122(86)$ & $0.39(0.22,0.70)^{* *}$ & $0.44(0.22,0.87)^{*}$ \\
\hline \multicolumn{5}{|l|}{ Knowledge on food diversification } \\
\hline Not knowledgeable & $25(9)$ & $259(91)$ & 1 & 1 \\
\hline knowledgeable & $93(42)$ & 131(58) & $7.35(4.51,11.99)^{* *}$ & $8.50(4.95,14.58)^{* *}$ \\
\hline \multicolumn{5}{|l|}{ Father's education } \\
\hline No education & $6(13)$ & $39(87)$ & 1 & 1 \\
\hline Primary education & $43(18)$ & 198(82) & $1.41(0.56,3.54)$ & $0.52(0.18,1.52)$ \\
\hline Secondary education and above & $69(31)$ & $153(69)$ & $2.93(1.19,7.25)^{*}$ & $0.69(0.23,2.10)$ \\
\hline \multicolumn{5}{|l|}{ Father's occupation } \\
\hline Daily laborer & $25(14)$ & $154(86)$ & 1 & 1 \\
\hline Employed & $35(36)$ & $62(64)$ & $3.48(1.92,6.28)^{* * *}$ & $2.14(0.99,4.59)$ \\
\hline Merchants & $44(26)$ & $123(74)$ & $2.20(1.28,3.80)^{* *}$ & $2.27(1.19,4.33)^{*}$ \\
\hline Others & $14(22)$ & $51(79)$ & $1.69(0.82,3.50)$ & $2.41(0.99,5.82)$ \\
\hline No of children $<5$ & & & & \\
\hline
\end{tabular}




\begin{tabular}{|c|c|c|c|c|}
\hline One & $70(24)$ & $223(76)$ & 1 & 1 \\
\hline Two & $44(24)$ & $137(76)$ & $1.02(0.66,1.58)$ & $1.03(0.56,1.90)$ \\
\hline 3 and above & $4(12)$ & $30(88)$ & $0.42(0.14,1.25)$ & $1.27(0.36,4.48)$ \\
\hline \multicolumn{5}{|l|}{ Family size } \\
\hline Less than 5 & $74(30)$ & $174(70)$ & 1 & 1 \\
\hline 5 or more & $44(17)$ & 216(83) & $0.48(0.31,0.73)^{* *}$ & $0.80(0.45,1.44)$ \\
\hline
\end{tabular}

(10.6\%)and Sinan Woreda of Northwest Ethiopia 13\% and lower than the studies done in Addis Ababa 59.9\% and Wolaita Sodo of Ethiopia (27.3\%) [20-25]. Geographical variation, study time, sample size and socio-economic differences might be the possible justification for the similarities and difference of optimum dietary diversity practice for children aged 6-23 months of age.

The current study found that $95 \%$ of mothers responded that their children were consumed foods prepared from grains, roots and tubers. This finding comes similar with study conducted in Southern part of Ethiopia [26]. This implies that, most infants and young children could get foods consist mainly of carbohydrates, which provide energy, but lacks enough protein, iron and Zink[27].

In the current study child age, mothers' education, media exposure, fathers' occupational status and knowledge of mothers on food diversification were significantly associated with dietary diversity practices. Children aged above one year were about three times more likely to consume a minimum dietary diversity compared with infants aged 6-11 months. This finding was similar with studies previously conducted in Dangila town of Northwest Ethiopia and Gorche district $[21,22]$. This might be due to the fact that most of the mother's start introduction of complementary food with milk only; because of their awareness that intestine of the younger child has poor ability to digest solid, semisolid and soft foods.

Mothers who had been exposed to different media like television and radio at least once a week or all time frequently were more likely to provide their children with adequate dietary diversity compared to those who have not exposed to the media at all. This finding is similar with study done in Dangila town and study done by Disha et, alusing EDHS 2011 and 2015[21, 28]. The possible reason could be the dissemination of child nutrition related information through medias in national radio and television have positive influence on mothers feeding practice, due to the fact that their nutritional knowledge could increase through regular exposure.

The study identified that $66 \%$ of mothers aged above 30 years were less likely to feed their child diversified food than their counterparts. It was similar with finding of the analysis of EDHS study that showed older women were giving their children less diverse diets [29]. The possible reason for this variation might be the difference in study setting and sociocultural difference.

Maternal knowledge on food diversification showed strong positive associations to their habit of dietary diversity feeding practice which is consistent with the finding of study conducted in Adea district of Oromia region, which showed mothers who were knowledgeable on dietary diversity were about eight times more likely to feed dietary diversity as compared with their counterparts [30]. The possible explanation for this finding is that, even if families can afford and different food varieties are available from the local markets, the awareness of mothers on the nutritional value of different variety of foods is a crucial factor to purchase it regularly for their children. The main problem identified in the current study is that, mothers list foods of the same group as different function (nutritional value) for children's health. The majority of mothers perceived that products of cereals which are the same food group such as pasta, rice and macaroni as different sources of nutrient for their children.

\section{Conclusion}

Optimum dietary diversity among children aged 6-23 months at the study area is low. A large proportion of mothers are feeding their children only from grain, roots and tubers or from dairy products due to their limited knowledge on diet diversification. Maternal education and availability/exposure to mass media were found as a positive predictor of optimum dietary diversity practice in the study area indicating the importance of maternal education on improvement of infant and young child feeding. So, Infant and young child feeding practice should be implemented according to the guideline at community level and Mothers should be educated about how to prepare the diversified diet from locale available food groups.

\section{Acknowledgment}

We thank Madda Walabu University for providing ethical clearance, data collectors, supervisor and study participants for their willingness to participate in the study.

\section{Funding}

This study was funded by Madda Walabu University.

\section{Authors' Contributions}

Conceptualization: SB was generated the research area and developed the proposal, and performed data analysis and prepared draft manuscript: TB, MT were involved in proposal development, analyses and reviewing the manuscript. BK was involved in data analysis and manuscript reviewing. All authors read and approved the final manuscript. 


\section{Ethics Approval and Consent to Participate}

We obtained ethical clearance from the Ethical review committee of Madda Walabu University. Verbal informed consent, which was prepared in written form and dictated to the respondents during data collection, was obtained from the study participants after explaining the purpose of the study and the benefits. Ethical review committee has approved this consent. Respondents were interviewed voluntarily, anonymously and confidentiality also was assured.

\section{References}

1. Black RE, Allen LH, Bhutta ZA, Caulfield LE, De Onis M, Ezzati $M$, et al. Maternal, group CUS: Maternal and child undernutrition: global and regional exposures and health consequences. Lancet. 2008;371(9608):243-260.

2. Onyango AW, Borghi E, de Onis M, del Carmen Casanovas M, Garza C. Complementary feeding and attained linear growth among 6-23-monthold children. Public Health Nutr. 2014;17(9):1975-1983.

3. Arimond M, Ruel MT. Dietary diversity is associated with child nutritional status: evidence from 11 demographic and health surveys. ] Nutr. 2004;134(10):2579-2585.

4. Nutrition IC. The achievable imperative for global progress. New York, NY: UNICEF;2013.

5. World Health Organization (WHO). 2008. Indicators for Assessing Infant and Young Child Feeding Practices. Geneva, Switzerland: WHO.

6. WHO. Infant and young child feeding, WHO, 2015 fact sheet 342 .

7. World Health Organization (WHO). 2008. Indicators for Assessing Infant and Young Child Feeding Practices. Geneva, Switzerland: WHO.

8. UNDP.Sustainable Development Goals (SDGs).

9. United Nations System Standing Committee on Nutrition (UNSCN). Nutrition and the Post-2015 Sustainable Development Goals: A technical note. 2014.

10. Federal Democratic Republic of Ethiopia (FDRE). 2008. National Nutrition Strategy (NNS). Addis Ababa, Ethiopia: FMOH

11. Federal Ministry of Health (FMOH) [Ethiopia]. 2015. National Nutrition Program, 2016- 2020. Addis Ababa, Ethiopia: FMOH.

12. Federal Democratic Republic of Ethiopia (FDRE). 2015. "Definition of Powers and Duties of the Executive Organs of the Federal Democratic Republic of Ethiopia Proclamation No. 916/2015." Federal Negarit Gazette, December 9, 20-15:8583.

13. Central Statistical Agency (CSA) [Ethiopia] and ICF. 2016. Ethiopia Demographic and Health Survey 2016. Addis Ababa, Ethiopia, and Rockville, Maryland, USA: CSA and ICF.

14. Beyene M, Gebeyehu A, Melese M: Dietary diversity, meal frequency and associated factors among infant and young children in Northwest Ethiopia: a cross- sectional study. BMC Public Health 2015, 15:1007.

15. WHO/UNICEF. Global strategy for infant and young child feeding. Geneva: WHO/UNICEF; 2005

16. Macías YF, Glasauer P: Guidelines for assessing nutrition-related knowledge, attitudes and practices - KAP Manual. Rome: Food and Agriculture Organization of the United Nations; 2014.

17. Gatahun EA,MeazaDemissie, Abyu DM. Dietary Diversity Feeding Practice and Determinants among Children Aged 6-23 Months in Kemba Woreda, Southern Ethiopia Implication for Public Health Intervention. J
Nutr Food Sci. 2015;19:1-10.

18. Belew AK, Ali BM, Abebe Z, Dachew BA. Dietary diversity and meal frequency among infant and young children: a community based study. Ital J Pediatr. 2017;43(1):73.

19. Gebremichael B, Egata G, Assefa N. Dietary diversity practice and associated factors among infants and young children in Haramaya town, Ethiopia. International Journal of Public Health Science (IJPHS) 2017;6(3):243-250.

20. Kumera G, Tsedal E, Ayana M. Dietary diversity and associated factors among children of orthodox Christian mothers/caregivers during the fasting season in Dejen District. North West Ethiopia Nutrition \& metabolism. 2018;15:16.

21. Beyene M, Worku AG, Wassie MM. Dietary diversity, meal frequency and associated factors among infant and young children in Northwest Ethiopia: a cross- sectional study. BMC Public Health. 2015;15:1007.

22. Dangura D, Gebremedhin S. Dietary diversity and associated factors among children 6-23 months of age in Gorche district, southern Ethiopia: cross-sectional study. BMC Pediatr. 2017;17(1):6.

23. Temesgen H, Yeneabat T, Teshome M. Dietary diversity and associated factors among children aged 6-23 months in Sinan Woreda, Northwest Ethiopia: a cross-sectional study. BMC nutrition. 2018;4(1):5.

24.Solomon D, Aderaw Z, Tegegne TK., Ethiopia. Int J Equity Health. 2017;16(1) Minimum dietary diversity and associated factors among children aged 6-23 months in Addis Ababa.

25. Mekonnen TC, Workie SB, Yimer TM, Mersha WF. Meal frequency and dietary diversity feeding practices among children 6-23 months of age in WolaitaSodo town, southern Ethiopia. J Health PopulNutr. 2017;36(1):18.

26. Kassa T, Meshesha B, Haji Y, Ebrahim J: Appropriate complementary feeding practices and associated factors among mothers of children age 6-23 months in Southern Ethiopia. BMC Pediatrics 2016, doi:10.1186/ s12887-016-0675-x

27. World Health Organization: Infant and young child feeding Model Chapter for textbooks for medical students and allied health professionals. vol. II. Geneva Switzerland; 2009.

28. Disha A, Tharaney M, Abebe Y, Alayon S, Winnard K: Factors associated with infant and young child feeding practices in Amhara Region and nationally in Ethiopia: Analysis of the 2005 and 2011 Demographic and Health Surveys. Washington, DC: Alive \& Thrive; 2015.

29. Headey D: An analysis of trends and determinants of child undernutrition in Ethiopia, 2000-2011, ESSP II Working Paper 70. Washington, DC and Addis Ababa, Ethiopia: International Food Policy Research Institute (IFPRI) and Ethiopian Development Research Institute (EDRI); 2014.

30. Agize A, Jara D, Dejenu G. Level of knowledge and practice of mothers on minimum dietary diversity practices and associated factors for 6-23-month-old children in Adea Woreda, Oromia. Ethiopia BioMed research international. 2017;2017:7204562. 